\title{
STRATEGI DAKWAH NAHDLATUL ULAMA DAN MUHAMMADIYAH DALAM MENANGKAL RADIKALISME DI KABUPATEN BONDOWOSO
}

\author{
Ade Nurwahyudi \\ Komunikasi dan Penyiaran Islam Pascasarjana IAIN Jember \\ adenurwahyudi90@gmail.com
}

\author{
Ahidul Asror \\ Institut Agama Islam Negeri Jember \\ ahidulasror@iain-jember.ac.id
}

Diunggah 11 September / Direvisi 15 Oktober / Diterima 15 November 2020

\begin{abstract}
Abstrac: The current radicalism movement has occurred in Indonesia. The emergence of this radical concept was caused by the existence of a group of Muslims who wants to purify religious teachings during the pre-independence period until now. In Bondowoso, this concept enters through children in elementary school (SD). from that incident, the two Islamic Community Organizations (Ormas) in Bondowoso; Nahdlatul Ulama and Muhammadiyah opposed, rejected the existence of this concept.

This research is descriptive qualitative based on case studies using the method of selecting subjects and data collection techniques through observation, interviews and documentation.

Based on the results of this research, it can be concluded that the preaching strategies of Nahdlatul Ulama and Muhammadiyah in counteracting radicalism in Bondowoso Regency are (1) both Nahdlatul Ulama and Muhammadiyah provide the understanding to all administrators related to radicalism. (2) Nahdlatul Ulama invites all components to be aware of radicalism movements at all levels, while Muhammadiyah through social media. (3) Nahdlatul Ulama held a Cadre Education for the Movement of Nahdlatul Ulama (PKPNU) and Muhammadiyah held regular studies. (4) Nahdlatul Ulama conducts Da'wah Cadre Training (PKD), Pancasila cadre training and Muhammadiyah conducts social da'wah. (5) Nahdlatul Ulama conducts recitation, seminars and Muhammadiyah through Friday sermons.
\end{abstract}

Keywords: Da'wah Strategy, Radicalism, Nahdlatul Ulama, dan Muhammadiyah

Korespondensi: Ade Nurwahyudi \& Ahidul Asror

IAIN Jember

adenurwahyudi837@gmail.com \& ahidulasror@iain-jember.ac.id 


\section{A. PENDAHULUAN}

Indonesia adalah bangsa yang berkembang dan mayoritas penduduknya beragama Islam, selain itu Indonesia juga dikenal dengan bangsa yang pluralistik, dimana tingkat karagamannya sangat tinggi yaitu dengan suku, ras, etnis, tradisi yang berbeda.Ini membuktikan bahwa Indonesia merupakan bangsa besar, bangsa yang penuh dengan nilai-nilai toleransi. Dibalik itu semua, keragaman tersebut dapat menimbulkan konflik laten dan berkepanjangan jika bangsa ini salah kelola. Adanya kesenjangan dan perbedaan dapat memicu konflik yaitu kesenjangan dan perbedaan ideologi (baca: agama). Karena itu seluruh komponen bangsa harus bisa menjaganya, sebab Indonesia merupakan salah satu negara multikultural terbesar di dunia. ${ }^{1}$

Terlepas dari banyaknya persoalan yang dihadapi bangsa Indonesia hingga saat ini seperti masalah ekonomi, politik, sosial dan termasuk munculnya gerakan radikalisme yang menjadi problem kuat dalam kehidupan berbangsa dan bernegara. Salah satu yang menjadi penyebab munculnya gerakan-gerakan paham radikal terkait dengan berbagai persoalan, seperti tidak adanya proses penegakan hukum secara adil dan sungguh-sungguh, serta ketidak adilan di sektor sosial, ekonomi, maupun politik. ${ }^{2}$

Munculnya paham radikal (baca; radikalisme) ini sangat bertentangan dengan ajaran agama Islam itu sendiri. Di mana agama ini (Islam) mengajarkan nilainilai toleransi sebagaimana pesan Allah dalam Al-Qur'an "Tidaklah kami mengutusmu (Muhammad) kecuali menjadi rahmat bagi seluruh alam" (QS. AlImron ; 107). ${ }^{3}$ Pesan tersebut mengindikasikan bahwa tidak boleh ada kekerasan di muka bumi atas nama apapun, termasuk gerakan radikal yang nyata-nyata banyak bertentangan dengan prinsip-prinsip ajaran agama itu sendiri.

Kalau kita cermati dalam perpektif kesejarahan dan kebahasaan bahwa kata radikal jika didekati secara etimologi, maka kata radikal berasal dari kata latin, radix atau radici, yang artinya "akar". Kalau dalam politik, istilah "radikal" ini mengacu pada perorangan, gerakan tersebut memperjuangkan perubahan sosial atau sistem

\footnotetext{
${ }^{1}$ Ainul Yaqin, Pendidikan Multikultural Cross-cultural Understanding untuk Demokrasi dan Keadilan (Pilar Media, Yogyakarta: 2005), 3

2 Sumtaki, Edy, et al. Syari'at Urgensi dan Konsekuensinya Islam: Sebuah Bunga Rampai, (Jakarta: Komunitas NISITA, 2003.), 7

${ }^{3}$ Achamad Siddhiq, Khittah Nahdliyyah (Khalista, Surabaya:2005), 12
} 
politik secara mendasar atau keseluruhan. Munculnya awal istilah kata"radikal" perlu diketahui pada abad ke-18 di Eropa dan ke-19 di Amerika Serikat. Predikat tersebut bisa dikenakan pada pemikiran atau paham tertentu, sehingga muncul istilah pemikiran yang radikal dan bisa pula berupa gerakan. Berdasarkan hal tersebut, radikalisme diartikan sebagai paham atau aliran keras yang menginginkan adanya perubahan atau pembaruan sosial dan politik dengan cara keras, kejam,ekstrem. Radikalisme agama ini berarti tindakan-tindakan ekstrim yang dilakukan oleh seseorang atau sekelompok orang yang cenderung menimbulkan kekerasan dengan mengatasnamakan agama. ${ }^{4}$

Berkembangnya gerakan radikalisme dan tindakan terorisme perlu diketahui bahwa tidak hanya dilakukan pemeluk ajaran agama Islam saja non muslim juga ada. Pada kasus yang terjadi tiga tahun kemaren bagaimana kronologi kejadian yang didalamnya ada unsur provokasi, teror dan aksi pembakaran serta perusakan yang terjadi masjid di Tolikara, wamena, papua, oleh sekelompok teroris kristen gereja injil yang terjadi pada tanggal 11 juli $2015 .^{5}$

Kasus tersebut diatas menandakan adanya masalah yang bersumber dari pemahaman ajaran agama yang radikal, ditandai dengan munculnya beberapa aliran dan madzhab baru yang mengatas namakan agama Islam seperti kelompok ISIS, alQaeda yang saat ini menjadi isu global. Karena mengingat penduduk Indonesia mayoritas beragama Islam, sehingga menjadi sasaran berkembangnya paham radikalisme dimana menurut Christina Parolin bahwa Indonesia akhir-akhir ini banyak berkembang isu-isu radikalisme. ${ }^{6}$

Adapun berbagia macam kasus terorisme dari tahun-ketahun yang terjadi di Indonesia yang dilakukan oleh orang pemeluk agama Islam maupun agama non Islam yang orang menyebutnya teroris, antara lain adalah kejadian bom bali tahun 2002 telah terjadi peristiwa pengeboman pada malam hari pada tanggal 12 oktober 2012 di tiga lokasi berbeda yaitu di paddy"s pub dan sari club di jalan legian, kuta,

${ }^{4}$ Ninin Prima Damayanti, dkk, "Radikalisme Agama Sebagai Salah Satu Bentuk Perilaku Menyimpang: Studi Kasus Front Pembela Islam", (Depok: Universitas Indonesia, Jurnal Kriminologi Indonesia Vol. 3 No. I Juni 2003), 45.

5https://www.eramuslim.com/berita/nasional/update-inilah-kronologi-pembakaran-masjid-di-wamenaoleh-teroris-kristen-tolikara.htm\#.XaxMnn8xXMx, diakses pada tanggal 20 Oktober 2019

${ }^{6}$ Christina Parolin, Radikal Spaces: Venues of Popular in London, 1790-c.1845 (Australia: ANU E Press, 2010), Cet. Ke-1, 3 
bali.7 Pengeboman di Jakarta tahun 2003 yaitu peristiwa bom di hotel JW marriot di kawasan Mega Kuningan, Jakarta. ${ }^{8}$ Terjadi kembali di Bali peledakan bom di tiga titik antara lain satu di Kuta dan dua di Jimbaran ada sedikitnya 23 orang tewas dan 196 lainnya luka-luka yang terjadi pada tanggal 1 oktober 2005.9 Bom Mega Kuningan 2009 ini terjadi di kawasan hotel JW marriott dan ritz-carlton di kawasan Mega Kuningan Jakarta selatan. ${ }^{10}$ Pada tahun 2016 terjadi aksi teror kembali,terjadi di jalan MH thamrin, Jakarta pusat yang terjadi pada tanggal 14 januari 2016.11

Fenomena peristiwa-peristiwa di atas agama Islam sendiri tidak mengajarkan kekerasan. Oleh karenanya di dalam berdakwah Islampun jauh dari kekerasan bahkan dalam dakwah Islam menekankan pada seruan hikmah, mengajarkan yang baik dan dalam membantahpun harus dengan yang baik, sesuai dalam Al-Qur'an Surat an- Nahl ayat 125:

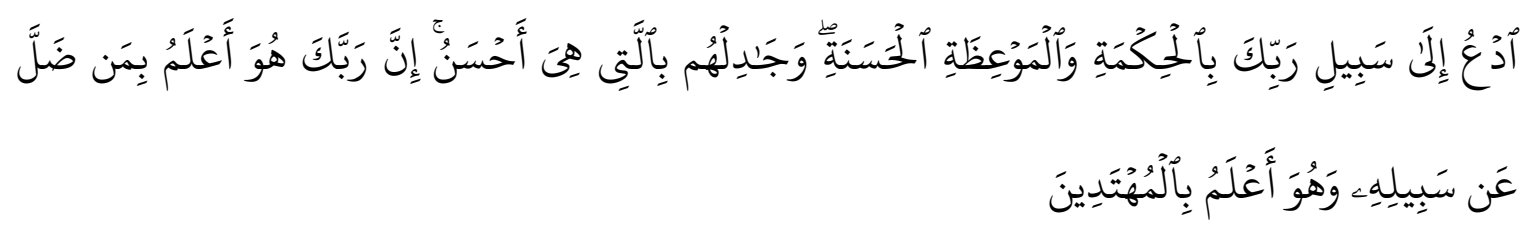

Artinya: Serulah (manusia) kepada jalan Tuhan-mu dengan hikmah dan pelajaran yang baik dan bantahlah mereka dengan cara yang baik. Sungguh Tuhanmu Dialah yang lebih mengetahui tentang siapa yang tersesat dari jalanya dan dialah yang lebih mengetahui orang-orang yang mendapat petunjuknya. ${ }^{12}$

Dari beberapa kejadian dan berdasarkan data surver mengenai intoleransi, gerakan radikalisme yang terjadi di Indonesia pada waktu itu dapat terlihat bahwa sentimen agama sangat kuat dan dapat dijadikan alat untuk menyerang kelompok agama lain, mulai dari kasus seperti kejadian perusakan tempat ibadah, aksi teror, peledakan bom, penutupan akses jalan yang mengakibatkan berbagai pertentangan, konflik bahkan sampai ke pertikaian antar agama. Peristiwa hal tersebut semakin memperlihatkan bahwa wacana pluralisme dan kebebasan agama masih menjadi problem yang krusial bagi kehidupan sosial keagamaan di Indonesia ditengah

\footnotetext{
${ }^{7}$ https://id.wikipedia.org/wiki/Bom_Bali_2002, diakses pada tanggal 21 Oktober 2019

8 https://id.wikipedia.org/wiki/Pengeboman_Hotel_Marriott_2003, diakses pada tanggal 21 Oktober 2019

${ }^{9}$ https://id.wikipedia.org/wiki/Bom_Bali_2005. Dikases pada tanggal 21 Oktober 2019

${ }^{10}$ https://id.wikipedia.org/wiki/Pengeboman_Jakarta_2009. Diakses pada tanggal 21 Oktober 2019

11https://nasional.kompas.com/read/2016/01/17/05300041/Ini.Kronologi.Teror.Bom.Jakarta.dari.Deti k.ke.Detik, diakses pada tanggal 21 Oktober 2019

12Al-Qur'an Terjemahan. Departemen Agama RI. (Bandung: CV Darus Sunnah, 2015), 281
} 
pemerintah mengupayakan membangun tatanan masyarakat yang lebih harmonis dan aman. Dari hasil data survey mengenai intoleransi dan radikalisme yang dilakukan pada 34 provinsi di Indonesia, menunjukkan bahwa potensi intoleran dan radikalisme di Indonesia sangat terbuka. Terdapat sebanyak 1520 responden yang mayoritas agama Islam dan rata-rata berumur 17 tahun keatas, terdapat sebanyak $59,9 \%$ berasal dari kelompok yang dibenci. Terus sebanyak 7,7\% responden yang bersedia melakukan tindakan radikal apabila ada kesempatan dan sebanyak 0,4\% justru pernah melakukan tindakan radikal. Namun dari hasil presentase tersebut tetap menghawatirkan. Sebab 7,7\% jika proyeksinya dari 150 juta umat Islam Indonesia, berarti terdapat sekitar 11 juta orang yang bersedia bertindak radikal. ${ }^{13}$

Munculnya gerakan radikalisme dan terorisme di Indonesia, pemerintah melakukan tindakan dengan mengeluarkan undang-undang baru tentang radikalisme. Didalam undang-undang No.5 Tahun 2018 pada pasal 12A ayat 1 (satu) tentang perubahan atas undang-undang nomor 15 tahun 2003 tentang penetapan paraturan pemerintah pengganti undang-undang nomor 1 tahun pemberantasan tidak pidana terorisme menjadi undang-undang. Yang mengatakan, bahwa setiap orang yang dengan maksud melakukan tindak pidana terorisme di wilayah Negara Kesatuan Republik Indonesia atau di negara lain, merencanakan, menggerakkan, atau mengorganisasikan tindak pidana terorisme dengan orang yang berada di dalam negeri dan atau di luar negeri atau negara asing dipidana dengan pidana penjara paling singkat 3 (tiga) tahun dan paling lama 12 (dua belas) tahun. ${ }^{14}$

Organisasi Kemasyarakatan (Ormas) Islam terbesar di Indonesia adalah Nahdlatul Ulama (NU) dan Muhammadiyah juga ikut angkat bicara tentang radikalisme yang mana menurut ketua umum Pengurus Besar Nahdlatul Ulama (PBNU) KH. Said Aqil Siroj mengatakan bahwa, berbagai macam tindakan yang digunakan untuk kekerasan, apalagi yang mengatasnamakan agama dengan cara menebarkan teror, kebencian, dan kekerasan bukanlah ciri ajaran Islam yang rahmatan lil alamin. ${ }^{15}$ Sedangkan dari ketua umum Pimpinan Pusat Muhammadiyah Haedar Nashir mengatakan meminta kepada elite politik untuk tidak memobilisasi

\footnotetext{
${ }^{13}$ Musa Rumbaru, Hasse J, Radikalisme Agama Legitimasi Tafsir Kekerasan di Ruang Publik. Jurnal Al-Ulum. Volume 16. Number 2. Desember 2016. 2

${ }^{14}$ http://ditjenpp.kemenkumham.go.id/arsip/ln/2018/uu5-2018bt.pdf, diakses pada tanggal 21 Oktober 2019

15https://nasional.republika.co.id/berita/nasional/hukum/18/05/13/p8ngwj430-enam-pernyataansikap-pbnu-terkait-bom-gereja-di-surabaya diakses pada tanggal 8 Desember 2019
} 
emosi agama, golongan, suku dan ras. Sebab radikalisme ini ada juga di dalam dunia politik. Oleh karenanya mobilisasi emosi agama, golongan, suku, ras yang membuat para pemilih ini bisa ikut jadi radikal. ${ }^{16}$

Tidak dapat dipungkiri, bahwa radikalisme dapat terjadi di berbagai kelompok, termasuk dalam dari NU dan Muhammadiyah. ${ }^{17}$ Sejak pemikiran extremisme dan radikalisme mulai masuk ke sejumlah kelompok Islam di Indonesia, NU dan Muhammadiyah, juga memiliki pengaruh yang sangat vital dalam membina masyarakat dan menjaga agar pemikiran extremisme dan radikalisme tidak berkembang lebih jauh lagi di kelompok masyarakat muslim Indonesia. ${ }^{18}$

Peran penting yang dimainkan NU dan Muhammadiyah sebagai organisasi muslim terbesar di Indonesia dalam melawan isu radikalisme dan extremisme Islam. Dimana NU dan Muhammadiyah juga sangat berpengaruh dalam memainkan proses mediasi dan menjembatani seluruh lapisan masyarakat dengan pemerintah, dan menjadi aktor penting dalam menciptakan dan menjaga perdamaian. NU dan Muhammadiyah juga sejak tahun 2002 telah lebih banyak melakukan melakukan tindakan serius untuk melawan citra Islam yang keras dan tidak toleran, dan berupaya membangun citra Islam yang damai dan melindungi seluruh umat beragama lainnya. ${ }^{19}$

Di Kabupaten Bondowoso telah terjadi peristiwa paham radikal mulai menyasar sekolah di Bondowoso, terdapat ada selebaran dukungan kepada gerakan radikalisme ini ditemukan di mading sekolah dasar. Kejadian tersebut terjadi di sekolah dasar negeri (SDN) Tamansari 1 Kecamatan Tamansari Kabupaten Bondowoso Jawa Timur.Dimana ada seorang siswa berinisial BN kelas enam SD waktu itu membuat tulisan di papan majalah diding (mading) sekolah tersebut. Hasil tulisan tersebut di antaranya berbunyi, "Ini kok bisa bertentangan dengan hukum agama dan hukum pancasila ini jelas-jelas melanggar hukum kenapa tidak dilindungi oleh pejabat penegak hukum (arti ISIS)."Tidak hanya itu, ada juga tulisan "Semua

\footnotetext{
16https://regional.kompas.com/read/2018/05/19/16131631/ketum-pp-muhammadiyah-ingatradikalisme-juga-ada-di-politikdiakses pada tanggal 8 Desember 2019

${ }^{17}$ Ayu Sutarto, Menjadi NU Menjadi Indonesia, Pemikiran KH Abdul Muchith Muzadi, (Surabaya :Kompyawisda jatim dan Khalista, 2008), 59

18https://kemlu.go.id/oslo/id/news/1134/upaya-nu-dan-muhammadiyah-berantas-radikalisme-danextremisme-tuai-apresiasi-dari-publik-norwegia diakses pada tanggal 8 Desember 2019

${ }^{19} \mathrm{https}$ ///kemlu.go.id/oslo/id/news/1134/upaya-nu-dan-muhammadiyah-berantas-radikalisme-danextremisme-tuai-apresiasi-dari-publik-norwegia diakses pada tanggal 8 Desember 2019
} 
pembunuh adalah saudara kita", "Teroris ini kok bisa bertentangan dengan agama", dan di baris terakhir, "Kami tidak takut polisi"..20

Selanjutnya, ada peristiwa aksi demo menentang acara milad fatimah yang rencananya digelar oleh Ikatan Jamaah Ahlul Bait (IJABI) di kampung Arab Bondowoso pada tanggal 5 sampai 6 april 2016 yaitu provokatif, 34 pengasuh pesantren pinta aparat batalkan acara syi'ah di Bondowoso. ${ }^{21}$

Baru-baru ini juga terjadi pada tanggal 11 november 2019 ini, berita pengajian umum yang tidak benar akan dilaksanakan atau hoax adanya, yang mana dalam pemberitaan tersebut akan mengadakan pengajian umum dalam rangka memperingati Maulid Nabi Muhammad SAW di Kejawan rt 21 Kecamatan Grujugan senin malam pukul 18.00 waktu Indonesia barat. Kegiatan tersebut merupakan bentuk strategi yang dilakukan oleh kelompok radikal dalam media sosial (medsos) untuk mempengaruhi jama'ah masyarakat Bondowoso dan disekitarnya. Meraka dengan sengaja mengemas pengajian tersebut bersama murid madrasah aliyah negeri di Bondowoso dan juga bersama tabligh akbar masjid agung at-taqwa Bondowoso. Terdapat pamflet yang tersebar media sosial tersebut mubalik yang akan dihadirkan dalam rangka pengajian tersebut adalah ustadz, Hutri Agus Priyudo, ${ }^{22 k i t a ~ t a h u ~ u s t a d z ~ t e r s e b u t ~ m e r u p a k a n ~ d a r i ~ o r g a n i s a s i ~ y a n g ~ i l e g a l ~ d a n ~}$ dilarang oleh pemerintah bahkan telah di bubarkan yaitu Hizbut Tahrir Indonesia (HTI).

Melihat fenomena peristiwa yang terjadi di luar Bondowoso maupun di Bondowoso, Organisasi Kemasyarakaan (Ormas) Islam yakni Nahdlatul Ulama dan Muhammadiyah melakukan dakwah tentang bahayanya gerakan radikalisme. Ormas Islam Muhammadiyah yang didirikan K.H. Ahmad Dahlan, lahir lebih dulu dari pada NU dimana di dalam melakukan strategi dakwahnya berpusat pada pembaharuan (tajdid) serta menjaga kemurnian Islam (purifikasi). Dalam rangka kegiatan pembaharuan dan pemurnian itu, selain dengan pemasyarakatan tajdid, untuk itu,

\footnotetext{
${ }^{20}$ http://rri.co.id/madiun/post/berita/240536/daerah/isis_pengaruhi_siswa_sd_di_bondowoso.htmldiak ses pada tanggal 21 Oktober 2019

${ }^{21}$ https://www.bangsaonline.com/berita/21300/provokatif-34-pengasuh-pesantren-minta-aparatbatalkan-acara-syiah-di-bondowoso diakses pada tanggal 21 Oktober 2019

${ }^{22} \mathrm{http}: / /$ hizbuttahrirhti.blogspot.com/2014/02/lds-hti-jember-berikan-penyuluhan.html?m=1diakses pada tanggal 21 Oktober 2019
} 
dakwah Muhammadiyah banyak diarahkan untuk memberantas segala hal yang berbau takhyul, bid'ah dan churafat. ${ }^{23}$

Strategi dakwah yang dilakukan oleh Pimpinan Daerah Muhammadiyah di Kabupaten Bondowoso dengan mengedepankan ajaran Islam sesuai dengan syari'at, diantaranya dengan pengajian rutin, membentuk lembaga bimbingan manasik haji, membangun budaya dialog dan pembinaan generasi muda, melalui dakwah media massa, dakwah kultural dan dakwah pemberdayaan umat di bidang pendidikan, ekonomi, sosial dan kesehatan. ${ }^{24}$ Dari model dakwah di atas, Muhammadiyah ingin menangkal radikalisme melalui pendekatan formalistik.

Sedangkan strategi dakwah NU dalam rangka menangkal radikalisme yaitu melalui gerakan-gerakan kultural seperti pengajian, forum-forum khusus seperti lailatul ijtimak yang diadakan di masing-masing MWCNU (Majlis Wakil Cabang Nahdlatul Ulama) yang berkedudukan ditingkat kecamatan sampai pada tingkat ranting NU yang tersebar diseluruh desa atau kelurahan.Adapun materi dakwahnya meliputi nilai-nilai keislaman yang lebih menekankan pada aspek toleran, moderat, I'tidal (berlaku lurus dan tidak bengkok) dan keseimbangan dalam aspek dunia dan akhirat. $^{25}$.

Strategi-strategi dakwah di atas, baik NU dan Muhammadiyah berusaha untuk mencegah dan berkembangnya adanya paham radikal tersebut di Kabupaten Bondowoso. Oleh karenanya NU dan Muhammadiyah memasang strategi dengan mengantisipasi masuknya pemahaman radikal yang menurutnya nanti akan dapat merusak tatanan idiologi masyarakat. Khususnya masyarakat Kabupaten Bondowoso.

Maka dari itu, peneliti ingin mengadakan penelitian dengan mengambil judul "Strategi Dakwah Nahdlatul Ulama dan Muhammadiyah Dalam Menangkal Radikalisme di Kabupaten Bondowoso".

Fokus penelitian ini adalah berkaitan dengan strategi dakwah Organisasi Kemasyarakaan (Ormas) Islam yakni Nahdlatul Ulama dan Muhammadiyah dalam menangkal radikalisme di Kabupaten Bondowoso. Berdasarkan fokus tersebut, tulisan ini memiliki rumusan masalah antara lain: Bagaimana konsep strategi dakwah Nahdlatul Ulama dan Muhammadiyah dalam menangkal radikalisme di

\footnotetext{
${ }^{23}$ Weinata Sairin, Gerakan Pembaharuan Muhammadiyah, (Jakarta: Pustaka, Sinar Harapan,1995), 48-49. ${ }^{24}$ Moh.Malik, Wawancara, Bondowoso, 13 Desember 2019

25Mas' ud Ali, Wawancara, Bondowoso, 13 Desember 2019
} 
Kabupaten Bondowoso?; Bagaimana pelaksanaan strategi dakwah Nahdlatul Ulama dan Muhammadiyah dalam menangkal radikalisme di Kabupaten Bondowoso ?

Berdasarkan rumusan masalah tersebut, tulisan ini memiliki tujuan penelitian antara lain: Ingin mendiskripsikan konsep strategi dakwah Nahdlatul Ulama dan Muhammadiyah dalam menangkal radikalisme di Kabupaten Bondowoso; Ingin mengetahui dan mendiskripsikan pelaksanaan strategi dakwah Nahdlatul Ulama dan Muhammadiyah dalam menangkal radikalisme di Kabupaten Bondowoso

\section{B. PEMBAHASAN}

\section{Pengertian Strategi Dakwah}

Strategi berasal dari bahasa Yunani: Strategia yang berarti kepemimpinan atas pasukan atau seni memimpin pasukan. Kata strategia bersumber dari kata strategos yang berkembang dari dari kata stratos (tentara) dan kata agein (memimpin). Istilah strategi dipakai dalam kontek militer sejak zaman kejayaan yunani, romawi sampai masa awal industrialisasi. Kemudian istilah strategi meluas ke berbagai aspek kegiatan masyarakat, termasuk dalam bidang komunikasi dan dakwah. Hal ini penting karena dakwah bertujuan melakukan perubahan terencana dalam masyarakat. ${ }^{26}$

Strategi adalah cara pengaturan untuk melaksanakan taktik itu. ${ }^{27}$ Bisa juga berarti kemampuan yang terampil dalam menangani dan merencanakan sesuatu. ${ }^{28}$

Strategi pada hakikatnya adalah perencanaan (planning) dan manajemen (management) untuk mencapai tujuan. Akan tetapi, untuk mencapai tujuan tersebut, strategi tidak berfungsi sebagai peta jalan yang hanya menunjukkan arah saja, melainkan harus mampu menunjukkan bagaimana taktik operasionalnya. ${ }^{29}$

Sedangkan pengertian dakwah dapat dilihat dari tiga sudut pandang yaitu dakwah dalam pengertian etimologi, terminologis, dan pengertian secara paradigmatis.

Menurut Sanusi dakwah adalah usaha-usaha perbaikan dan pembangunan terhadap masyarakat, memperbaiki kerusakan-kerusakan, melenyapkan kebatilan,

\footnotetext{
${ }^{26}$ Anwar Arifin, Dakwah Kontemporer: Sebuah Studi Komunikasi (Yogyakarta: Graha Ilmu, 2011), 227

${ }^{27}$ Kustadi Suhandang, Retorika: Strategi, Teknik dan Taktik Berpidato (Bandung: Penerbit Nuansa, 2009), 90

${ }^{28}$ Syukriadi Sambas \& Acep Aripudin, Dakwah Damai: Pengantar Dakwah Antar budaya (Bandung: PT. Remaja Rosdakarya, 2007), 138

${ }^{29}$ Onong Uchjana Effendy,Ilmu Komunikasi: Teori dan Praktek (Bandung: PT Remaja Rosdakarya, 2007), 32
} 
kemaksiatan dan ketidak wajaran dalam masyarakat. Dengan demikian, dakwah berarti memperjuangkan yang ma'ruf atas yang munkar, memenangkan yang hak atas yang batil. ${ }^{30}$

Istilah dakwah yang bersifat untuk pembinaan ini adalah suatu usaha mempertahankan, meletarikan dan menyempurnakan umat manusia agar tetap beriman kepada allah, dengan menjalankan syariatnya sehingga menjadi manusia yang hidup bahagia dunia dan akhirat. ${ }^{31}$

Didalam Al-Qur'an juga mengandung dasar hukum perintah untuk melaksanakan dakwah, yaitu di dalam surat Ali Imran ayat 104 yang berbunyi :

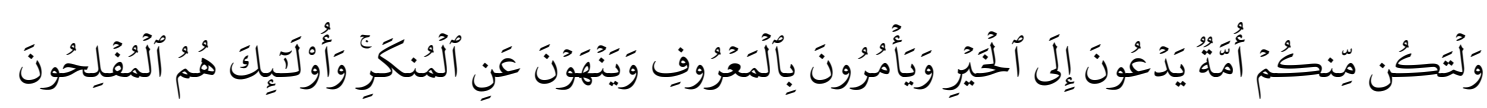

Artinya : Dan hendaklah ada di antara kamu segolongan umat yang menyeru kepada kebajikan, menyuruh kepada yang ma'ruf dan mencegah dari yang munkar; merekalah orang-orang yang beruntung. ${ }^{32}$

Disini adapun macam-macam pengertian strategi dakwah menurut para ahli antara lain :

a. Menurut Al-Bayanuni, strategi dakwah adalah ketentuan-ketentuan dakwah dan rencana-rencana yang dirumuskan untuk kegiatan dakwah. ${ }^{33}$

b. Abu Zahrah, Strategi dakwah Islam adalah perencanaan dan penyerahan kegiatan dan operasi dakwah Islam yang dibuat secararasional untuk mencapai tujuan-tujuan Islam yang meliputi seluruh dimensi kemanusiaan. ${ }^{34}$

c. Asmuni Syukir, strategi dakwah artinya sebagai metode, siasat, taktik atau maneuver yang dipergunakan dalam aktivitas (kegiatan) dakwah. ${ }^{35}$

d. Moh. Ali Aziz, Strategi dakwah adalah perencanaan yang berisi rangkaian kegiatan yang didesain untuk mencapai tujuan dakwah tertentu. ${ }^{36}$

Untuk menjalankan strategi dakwah tentunya pelaku dakwah harus memperhatikan asas-asas yang menentukan dalam strategi dakwah tersebut. Adapun Asas-asas tersebut antara lain :

\footnotetext{
${ }^{30}$ Sanusi, Pengantar Studi Ilmu Dakwah, (Semarang: Fakultas Dakwah IAIN Walisongo. 1985), 11

${ }^{31}$ Ahidul Asror,Paradigma Dakwa Konsepsi dan Dasar Pengembangan Ilmu, (Yogjakarta,LkiS, 2018), 3

32Departemen Agama RI, Al-Qur,an dan Terjemahnya (Jakarta: CV. Penerbit J-ART, 2004), 63

33 Moh. Ali Aziz, Ilmu Dakwah, Jakarta: (Prenada Media,2009), 351

${ }^{34}$ Syukriadi Sambas \& Acep Aripudin, Dakwah Damai: Pengantar Dakwah Antarbudaya,...... 138

35 Asmuni Syukir, Dasar-Dasar Strategi Dakwah Islam (Surabaya: Al-Ikhlas, 1983), 32

36 Moh. Ali Aziz, Ilmu Dakwah. 349
} 
1) Azas filosofis: azas ini terutama membicarakan masalah yang erat hubungannya dengan tujuan-tujuan yang hendak dicapai dalam proses atau dalam aktifitas dakwah.

2) Azas kemampuan dan keahlian Da`i (achievement and professional).

3) Azas sosiologis: azas ini membahas masalah-masalah yang berkaitan dengan situasi dan kondisi sasaran dakwah. Misalnya politik pemerintahan setempat, mayoritas agama di daerah setempat, filosofis sasaran dakwah. Sosiokultural sasaran dakwah dan sebagainya.

4) Azas psikologis: azas ini membahas masalah-masalah yang erat kaitannya dengan hubungannya dengan kejiwaan manusia. Seorang Da`i adalah manusia, begitupun sasaran dakwahnya yang memiliki karakter (kejiwaan) yang unik yakni berbeda satu sama lainnya. Apalagi masalah agama, yang merupakan masalah ideologi atau kepercayaan tak luput dari masalah-masalah psychologis sebagai azas (dasar) dakwahnya.

5) Azas efektifitas dan efisiensi: azas ini maksudnya adalah di dalam aktifitas dakwah harus berusaha menyeimbangkan antara biaya, tenaga dan waktu maupun tenaga yang dikeluarkan dengan pencapaian hasilnya, bahkan kalau bisa waktu, biaya dan tenaga sedikit dapat memperoleh hasil yang semaksimal mungkin. Dengan kata lain ekonomis biaya, tenaga dan waktu tapi dapat mencapai hasil yang semaksimal mungkin atau setidak-tidaknya seimbang antara keduanya. ${ }^{37}$

Melihat azas-azas strategi dakwah di atas, seorang da'i perlu sekali memiliki pengetahuan-pengetahuan yang erat hubungannya dengan azas-azas tersebut. Adapun Ilmu-ilmu yang sekurang-kurangnya harus dimiliki seorang da'i antara lain tentang :

1. Kepribadian seorang da'i

2. Tujuan-tujuan dakwah

3. Materi Dakwah

4. Masyarakat sebagai obyek dakwah

5. Metodologi dakwah dan

6. Media dakwah. ${ }^{38}$ 
Artinya dari azas-azaz dan kreteria ilmu seorang da'i ini menjadi modal dasar agar para da'i NU dan Muhammadiyah dalam berdakwah nanti bisa mengetahui bagaimana menyampaikan hal yang diinginkan bisa mengena sesuai dengan harapan dan tujuan.

\section{Bentuk-bentuk Strategi Dakwah}

Menurut Muhammad Abu Fatah Al Bayanuni (Al-Bayanuni)strategi dakwah dibagi menjadi tiga bentuk antara lain : 39

a. Strategi Sentimental (al-manhaj al-athifi)

Strategi sentimental adalah dakwah yang memfokuskan aspek hati dan menggerakkan prasaan dan batin mitra dakwah. Memberi mitra dakwah nasihat yang mengesankan, memanggil dengan kelembutan, atau memberikan pelayanan yang memuaskan merupakan metode yang dikembangkan dalam strategi ini.

b. Strategi Rasional (al-manhaj al-aqlī)

Strategi rasional adalah dakwah dengan beberapa metode yang memfokuskan pada aspek akal pikiran. Strategi ini mendorong mitra dakwah untuk berpikir, merenungkan, dan mengambil pelajaran. Penggunaan hukum logika, diskusi, atau penampilan contoh dan bukti sejarah merupakan beberapa metode dari strategi rasional. Disini Al-Qura'an mendorong penggunaan strategi rasional dengan terminologi, antara lain :

1. Tafakkur, adalah menggunakan pemikiran untuk mencapainya dan memikirkanya.

2. Tadzakkur, merupakan menghadirkan ilmu yang harus dipelajari setelah dilupakan.

3. Nazhar, ialah mengarahkan hati untuk berkonsentrasi pada obyek yang sedang diperhatikan.

4. Taammul, berarti mengulang-ngulang pemikiran hingga menemukan kebenaran dalam hatinya.

5. I'tibar, Bermakna perpindahan dari pengetahuan yang sedang dipikirkan menuju pengetahuan yang lain.

6. Tadabbur, adalah suatu usaha memikirkan akibat-akibat setiap masalah.

7. Istibshar, ialah mengungkap sesuatu atau menyingkapnya, serta memperlihatkannya kepada pandangan hati. ${ }^{40}$ 
c. Strategi Indrawi (al-manhaj al-hissy)

Strategi ini juga dapat dinamakan dengan strategi eksperimen atau strategi ilmiah. strategi tersebut didefinisikan sebagai sistem dakwah atau kumpulan metode dakwah yang berorientasi pada pancaindra dan berpegang teguh pada hasil penelitian dan percobaan. Di antara metode yang dihimpun oleh strategi ini adalah praktik keagamaan, keteladanan, dan pentas drama.

Penentuan strategi dakwah juga bisa didasarkan surah al-Baqarah (2) ayat 129 dan 151, Ali Imraan (3) ayat 164 dan al-jumu'ah (62) ayat 2. Ketiga ayat ini memiliki pesan yang sama, yaitu tentang tugas para rasul sekaligus bisa dipahami sebagai strategi dakwah. ${ }^{41}$

Didalam ketiga ayat yang disebutkan diatas mengisyaratkan tiga strategi dakwah antara lain :

1) Strategi Tilawah (membacakan ayat-ayat Allah SWT). Dengan strategi ini mitra dakwah diminta mendengarkan penjelasan pendakwah atau mitra dakwah membaca sendiri pesan yang ditulis oleh pendakwah.

2) Strategi Tazkiyah (menyucikan jiwa). Jika strategi tilawah melalui indra pengengaran dan indra penglihatan, maka metode tazkiyah melalui aspek kejiwaan.

3) Strategi Ta'lim. Strategi ini hampir sama dengan strategi tilawah, yakni keduanya mentransformasikan pesan dakwah. ${ }^{42}$

Dari teori tentang strategi dakwah dan bentuk-bentuk strategi dakwah menjadi teori strategi dakwah Nahdlatul Ulama dan Muhammadiyah di Kabupaten Bondowoso sebagai strategi dakwah untuk menyampaikan dakwahnya untuk menangkal radikalisme.

\section{Radikalisme dan Terorisme}

Sekarang ini di Indonesia masalah gerakan radikalisme bukan menjadi fenomena baru dan harus di waspadai pula gerakannya. Timbulnya faham radikal tersebut disebabkan oleh adanya sekelompok umat Islam yang menginginkan pemurnian ajaran agama pada masa prakemerdekaan sampai sekarang ini. Dalam konteks ini, sebagian umat Islam dianggap tidak lagi berjalan sebagaimana ajaran yang telah diajarkan oleh Rasulullah SAW dan tuntunan dalam kitab suci Al-Qur'an.

40 Moh.Ali Aziz, Ilmu Dakwah (Jakarta:Kencana,.2004), 301-302

${ }^{41}$ Moh. Ali Aziz, Ilmu Dakwah.

${ }^{42}$ Moh. Ali Aziz, Ilmu Dakwah. 304 
Oleh karena itu Islam menentang radikalisme yang mana Allah SWT telah menyempurnakan ajaran Islam dan menjadikan umat Islam sebagai umat terbaik yang akan menjadi saksi atas umat yang lain, sesuai dalam Al-Qur'an Surat AlBaqarah ayat 143 yang berbunyi :

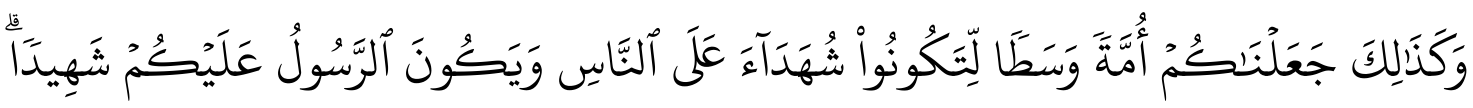

Artinya : Dan demikian (pula) Kami telah menjadikan kamu (umat Islam), umat yang adil (terbaik) dan pilihan agar kamu menjadi saksi atas (perbuatan) manusia dan agar Rasul (Muhammad) menjadi saksi atas (perbuatan) kamu. [AlBaqarah/2:143] ${ }^{43}$

Oleh sebab itu radikal disini merupakan sebuah komunitas yang menjadi sorotan oleh semua kalangan baik agama Islam maupun agama non Islam pada umumnya. Kegiatan aktivitasnya dan gerakannya yang mereka lakukan selama ini pada umunya menimbulkan pro dan kontra. Tindakan kekerasan yang dikemas dalam konsep jihad merupakan ciri khas dari gerakan mereka tentunya. Dari mana dan landasan apa yang mereka gunakan, maka perlu dipahami definisi dan siapa penganut paham tersebut. Secara terminologi definisi radikal sulit dirumuskan.Namun bukan berarti radikal tidak bisa dimaknai secara keseluruhan. Radikal sering dikaitkan dengan teroris. Bahkan sudah menjadi icon bahwa penganut paham Islam radikal adalah mereka komunitas teroris. Meski hampir semua pemuka Islam jelas menolak adanya pengkaitan antara Islam dengan terorisme. ${ }^{44}$

Menurut Kalidjernih (2010) mengatakan radikalisme adalah suatu komitmen kepada perubahan keseluruhan yakni yang menantang struktur dasar atau fundemental tidak hanya pada lapisan-lapisan super-fisial. ${ }^{45}$

\section{Metodologi}

Penelitian ini menggunakan analisis data deskriptif kualitatif. Analisis data dimulai dengan menyusun secara sistematik data yang diperoleh dari hasil wawancara, catatan lapangan dan dokumentasi, dengan cara mengorganisasikan data dalam katagori,

\footnotetext{
${ }^{43} \mathrm{Al}$-Qur'an dan Terjemahan. Departemen Agama RI. (Bandung: CV Darus Sunnah, 2015), 36

${ }^{44}$ Muhammad Asfar, Ed, Islam Lunak Islam Radikal Pesantren, Terorisme Dan Bom Bali, (Surabaya: Jp Pres, 2003), 57

${ }^{45}$ Muhammad Khomsun Soleh, Menangkal Masuknya Paham Radikalisme Pada Masyarakat Desa,(Temanggung, Jawa Tengah : 2019), 6
} 
menjabarkan ke dalam unit-unit, melakukan sintesa, menyusun ke dalam pola, memilih mana yang penting dan yang akan dipelajari dan membuat kesimpulan sehingga dipahami diri sendiri maupun orang lain. ${ }^{46}$ Miles dan Huberman, mengemukakan bahwa aktifitas dalam analisis data kualitatif dilakukan secara interaktif dan berlangsung secara terus menerus sampai tuntas, sehingga datanya sudah sampai lengkap. Adapun aktivitas dalam analisa data antara lain :

1. Reduksi Data (Data Reduction)

Reduksi data merupakan bentuk analisis data yang merangkum, memilih halhal yang pokok, memfokuskan pada hal-hal yang penting, dicari tema dan polanya. Dengan demikian data yang direduksi akan memberikan gambaran yang jalas, dan mempermudah peneliti untuk melakukan pengumpulan selanjutnya dan mencari bila diperlukan. ${ }^{47}$

2. Penyajian Data (Data Display)

Dalam penelitian kualitatif, penyajian data bisa dilakukan dalam bentuk urian singkat, bagan, hubungan antar katagori, flowchart dan sejenisnya.Dalam ini bahwa yang paling sering digunakan untuk mengkaji data dalam penelitian kualitatif adalah teks yang bersifat naratif. ${ }^{48}$

3. Verifikasi (Conclusion Drawing)

Menurut Miles dan Hubermas Verifikasi adalah penarikan kesimpulan atau verifikasi data. Kesimpulan dalam hal ini merupakan temuan baru yang sebelumnya belum pernah ada. Temuan dapat berupa deskripsi atau gambaran suatu obyek yang sebelumnya masih remang-remang atau gelap sehingga setelah diteliti menjadi jelas, dapat berupa hubungan kausal atau interaktif, hiptesis atau teori. ${ }^{49}$

\section{Temuan dan Diskusi}

Berdasarkan temuan hasil dari wawancara dan observasi dilapangan bahwa strategi dakwah Nahdlatul Ulama dan Muhammadiyah dalam menangkal radikalisme khususnya di Kabupaten Bondowoso. Berdasarkan fokus penelitian terdapat beberapa temuan dilapangan antara lain antara lain,

\footnotetext{
${ }^{46}$ Sugiono, Metode Penelitian Kuantitatif Kualitatif dan R\&D (Bandung: Alfabeta, 2014), 244

${ }^{47}$ Sugiono, Metode Penelitian Kuantitatif .........................................,246-247

${ }^{48}$ Sugiono, Metode Penelitian Kuantitatif...

${ }^{49}$ Sugiono, Metode Penelitian Kuantitatif. 


\section{a. Konsep Strategi Dakwah Nahdlatul Ulama dan Muhammadiyah Dalam Menangkal Radikalisme di Kabupaten Bondowoso}

Tentunya didalam proses penelitian, peneliti telah menemukan beberapa temuan tentang bagaimana konsep strategi dakwah Nahdlatul Ulama dan Muhammdiyah dalam menangkal radikalisme di Kabupaten Bondowoso antara lain sebagai berikut :

1) Nahlatul Ulama dan Muhammadiyah sama-sama memberikan pemahaman dalam kegiatan dakwah kepada seluruh pengurus terkait tentang radikalisme

Berdasarkan hasil temuan dilapangan dari hasil wawancara dan observasi bahwa konsep strategi dakwah Nahdlatul Ulama dan Muhammadiyah dalam menangkal radikalisme di Kabupaten Bondowoso sama-sama memberikan pemahaman dalam kegiatan dakwa atau penjelaskan kepada seluruh pengurusnya sampai ke anggota baik dari segela tingkatan.

Nahdlatul Ulama juga berantisipasi terhadap gerakan radikal tersebut dari segala tingkatan baik di tingkat pusat, cabang sampai ke tingkat Kecamatan hingga kedesa. Kemudian dari Muhammadiyah sendiri juga samasama memberikan pemahaman tentang radikalisme kepada angota atau pengurus yang ada di struktural atau pemberian pemahaman untuk kalangan internal sendiri..

2) Nahdlatul Ulama mengajak seluruh komponen untuk mewaspadai gerakan radikalisme disegala tingkatan sedangkan Muhammadiyah melalui media sosial.

Kemudian selanjutnya untuk konsep strategi dakwah Nahdlatul Ulama dan Muhammadiyah dalam manangkal radikalisme di Kabupaten Bondowoso, Disini peneliti berdasarkan hasil wawancara dan observasi dilapangan bahwa Nahdlatul Ulama untuk konsep strategi dakwahnya yang dilakukan adalah mengajak kepada seluruh komponen kiai termasuk pengurus di semua tingkatan untuk bisa mewaspadai gerakan-gerakan radikalisme yang agar tidak masuk ke sekolah atau kemasyarakat.

Kemudian konsep strategi dakwah Muhammadiyah yang dilakukan untuk menangkal radiklisme adalah melalui media sosial artinya 
Muhammadiyah lebih mengawasi, mewaspai semua anggota-anggota atau pengurusnya yang ada di grub media sosial seperti facebook, whatsapp atau kelompok-kelompok yang ada pengurus, jama'ahnya untuk tidak terlibat dengan gerakan radikalisme.

\section{b. Pelaksanaan Strategi Dakwah Nahdlatul Ulama dan Muhammadiyah Dalam Menangkal Radikalisme di Kabupaten Bondowoso}

Berdasarkan hasil wawancara dengan para pengurus Nahdlatul Ulama di Kabupaten Bondowoso dan para pengurus Muhammadiyah di Kabupaten Bondowoso. Terdapat beberapa temuan atau jawaban tentang bagaimana pelaksananaan strategi dakwah Nahdlatul Ulama dan Muhammadiyah dalam menangkal radikalisme selama ini adalah sebagai berikut ini :

1) Nahdlatul Ulama mengadakan kegiatan Pendidikan Kader Penggerak Nahdlatul Ulama (PKPNU), Pelatihan Kader Dakwah (PKD), pelatihan kader pancasila dan Muhammadiyah mengadakan kajian rutin serta dakwah sosial.

Upaya yang dilakukan oleh Nahdlatul Ulama Kabupaten Bondowoso untuk menangkal radikalisme khususnya di Kabupaten Bondowoso adalah dengan mengadakan pengkaderan dalam bentuk Pendidikan Kader Penggerak Nahdlatul Ulama (PKPNU). Kegiatan pelaksanaan pengkaderan ini sebagai bentuk upaya untuk memberikan pemahaman, penguatan dan ilmu tentang ke-NU-an kepada seluruh kader dan pengurus di segala tingkatan baik tingkat banom ataupun lembaga. Taktik strategi dakwah tersebut telah menggunakan strategi rasional yakni mendorong mitra dakwah untuk berpikir, mengambil pelajaran dalam kegiatan tersebut. Kegiatan ini merupakan bagian dari berdakwah dengan mengadakan kegiatan pengkaderan yang dilakukan oleh jajaran pengurus disegala tingkatan dengan mengadakan Pendidikan Kader Penggerak Nahdlatul Ulama yang dilaksanakan di pondok pesantren Nurut Taqwa Cermee yang dihadiri Bupati Bondowoso KH. Salwa Arifin.

Kegiatan Pendidikan Kader Penggerak Nahdlatul Ulama ini diikuti oleh seluruh kepengurusan Nahdlatul Ulama disegala tingkatan Majelis Wakil Cabang Nahdlatul Ulama (MWCNU) di tingkat Kecamantan beserta ranting NU-nya, baik dari jajaran pengurus Badan Otonom (Banom) Nahdlatul Ulama 

dan lembaganya serta Pondok-pondok pesantren yang ada di Kabupaten Bondowoso.

Pelatihan tersebut tidak lain adalah untuk memberikan pemahaman, penguatan didalam berjam' iyah agar nantinya para kader yang ikut didalam kegiatan tersebut yang sudah digembleng selama tiga hari tidak mudah terpengaruh oleh paham yang bersembrangan dengan ahlussunah wal jama'ah.

Dari paparan diatas teori Al-Bayanuni dengan bentuk strategi rasional telah digunakan dengan mengajak para peserta untuk berpikir, merenung dan mengajak untuk belajar dalam kegiatan pengkaderan tersebut. Begitu pula teori Asmuni Syukir tentang strategi dakwah juga sudah diterapkan oleh Nahdlatul Ulama Kabupaten Bondowoso sebagai bentuk siasat, taktik dan strategi dakwah untuk memberikan pemahaman, penguatan serta menangkal paham apapun yang nantinya bisa masuk ke masyarakat. Artinya kedua teori tersebut diatas telah diterapkan dan digunakan sebagai bentuk strategi dakwah didalam pelaksanaan berdakwah.

Untuk Muhammadiyah dalam pelaksanaan strategi dakwahnya terkait tentang radikalisme sering melakukan kegiatan-kegiatan diskusi atau kajian rutin yang bersifat internal. Kegiatan kajian tersebut hanya diikuti oleh jajaran pengurus dan anggota sebagai bentuk bahan diskusi untuk mencari jalan keluar tentang paham tersebut agar tidak semakin meluas dan juga sebagai tambahan ilmu pengetahuan untuk menangkal paham tersebut. Kajin setiap bulan ini secara tidak langsung telah menerapkan strategi rasional sebagai upaya untuk memberikan pemahaman dan pengertian dengan kepada mitra dakwah dengan mendatang berbagai nara sumber yang hadal yang berkaitan bertentangan dengan keagamaan kepada para jama'ah. Artinya dari penjelasan tersebut teori Al-Bayanuni sudah sesuai dan digunakan salah satu bentunnya strateginya adalah strategi rasional yakni mengajak para jama'ah untuk mengambil pelajaran, berpikir apa yng disampaikan nara sumber.

Selain itu Nahdlatul Ulama dalam pelaksanaan untuk menangkal radikalisme di Kabupaten Bondowoso, Nahdlatul Ulama berdasarkan wawancara dan observasi dilapangan mengadakan pelatihan kader dakwah 
ini merupakan suatu pengkaderan yang dikemas dengan pelatihan yang berisi tentang bagaimana berdakwah yang ramah, berdakwah yang toleran, berdakwah yang juga menyejukkan kepada jama'ah yang didalamnya juga berdakwahnya untuk menangkal radikalisme.

Kegiatan pelatihan tersebut pesertanya diikuti oleh para jama'ah atau masyarakat dan pelaksanaanya dilaksanakan di perkecamatan. Kemudian Nahdlatul Ulama Kabupaten Bondowoso juga melakukan kegiatan pelatihan kader pancasila dalam rangka ingin memberikan pemahaman tentang pancasila yang pesertanya para pelajar Sekolah Menengah Atas (SMA) atau sederajatnya yang ada di Kabupaten Bondowoso.

Di Muhammadiyah didalam pelaksanaan strategi dakwah untuk menangkal radikalisme dengan cara mengadakan dakwah sosial, dakwah sosial ini adalah kegiatan dakwah sosial ini meliputi pemberian bantuan dibidang pendidikan, kesehatan. Disamping itu juga kegiatan dakwah ini juga menyantuni orang-orang miskin, anak-anak yatim yang didalamya diselengi dengan dakwah tentang radikalisme. Sasaran gerakan dakwah sosial masyarakat miskin, anak yatim dan di bidang pendidikan dan kehatan adalah ditingkat SD, SMP, SMA, SMK.

Kegiatan gerakan dakwah sosial yang dikemas dengan pemberian santunan yang dilakukan oleh ibu-ibu Aisyiyah Muhammadiyah yang ada ditingkat Kecamatan Kota Bondowoso artinya telah menerapkan strategi indrawi dengan sasaranya adalah kepada masyarakat miskin, anak-anak yatim yang dilaksanakan di rumah tanfidz Qur'an Dabasah. Maka dengan penjelasan diatas artinya teori strategi indrawi ini jelas sudah diterapkan dalam kegiatan dakwah sosial.

2) Nahdlatul Ulama mengadakan pengajian, seminar dan Muhammadiyah melalui khotbah juma'at

Nahdlatul Ulama didalam pelaksanaan strategi dakwahnya dalam menangkal radikalisme selama ini berdasarkan hasil wawancara dan observasi dengan mengadakan pengajian yang bisa dilaksanakan oleh seluruh pengurus Nahdlatul Ulama. Selain itu pelaksanaan lainnya Nahdlatul Ulama adalah mengadakan seminar tentang deradikalisasi yang dilakukan oleh kader-kader Nahdlatul Ulama baik yang ada di Dewan Pendididikan, 
Lembaga Syadaya Masyarakat atau LSM dan itu semuanya sebagai bentuk untuk memberikan pemahanan tentang radikalisme.

Kedua kegiatan tersebut didalam pelaksanaanya bisa ikuti oleh seluruh jama'ah, anggota pengurus dan para pelajar yang ada di Kabupaten Bondowoso dengan tujuan untuk memberikan penguatan, pemahaman tentang apa itu radikalisme.

Sedangkan Muhammadiyah dalam pelaksanaannya strategi dakwah yang dilakukan untuk menangkal radikalisme di Kabupaten Bondowoso adalah dengan cara membentengi masjid-masjid yang ada khususnya masjid Muhammadiyah dan para da'i-da'i serta jama'ahnya agar tidak dimasuki dengan gerakan radikalisme.

Hal tersebut merupakan salah satu bentuk untuk menjaga masjidmasjid tersebut agar tidak dimasukan paham tersebut dengan cara melalui khotbah jum'at yang didalamnya menyingung atau membahas tentang gerakan radikalisme. Kerana Muhammadiyah tidak menjaga seluruh para jama'ah yang ada.

\section{KESIMPULAN DAN SARAN}

Berdasarkan hasil temuan penelitian tentang strategi dakwah Nahdlatul Ulama dan Muhammadiyah dalam menangkal radikalisme di Kabupaten Bondowoso, maka peneliti dapat menyimpulkan bahwa sebagai berikut :

1. Nahdlatul Ulama dan Muhammadiyah Kabupaten Bondowoso strategi dakwahnya dalam menangkal radikalisme, kedua Ormas Islam tersebut samasama memberikan pemahaman dalam kegiatan dakwah kepada seluruh pengurus terkait tentang radikalisme.

2. Nahdlatul Ulama di Kabupaten Bondowoso strategi dakwah dalam rangka untuk menangkal radikalisme disini adalah mengajak seluruh komponen untuk mewaspadai radikalisme disegala tingkatan sedangkan. Sedangkan Muhammadiyah Kabupaten Bondowoso strategi dakwahnya untuk menangkal radikalisme melalui media sosial.

3. Nahdlatul Ulama Kabupaten Bondowoso strategi dakwahnya dalam rangka menangkal radikalisme diantaranya adalah mengadakan kegiatan Pendidikan Kader Penggerak Nahdlatul Ulama (PKPNU), Pelatihan Kader Dakwah (PKD), 
pelatihan kader pancasila sedangkan Muhammadiyah Kabupaten Bondowoso untuk mengadakan kajian rutin serta dakwah sosial.

4. Nahdlatul Ulama Kabupaten Bondowoso strategi dakwah untuk menangkal radikalisme adalah mengadakan kegiatan pengajian, seminar dan Muhammadiyah Kabupaten Bondowoso strategi dakwahnya dalam menangkal radikalisme melalui khotbah juma'at kepada para jam'ah.

Berdasarkan hasil temuan dan paparan penelitian, maka disampaikan saran terhadap hasil penelitian adalah :

1. Bagi pengurus Nahdlatul Ulama dan Muhammdiyah di Kabupaten Bondowoso hendaknya terus memberikan pemahaman, kewaspadaan kepada jama'ahnya baik dari sektor pendidikan, kesehatan dan lain sebagainya karena itu sebagai upaya untuk menangkal radikalisme.

2. Bagi pengurus Nahdlatul Ulama Kabupaten Bondowoso dan pengurus Muhammadiyah Kabupaten Bondowoso hendaknya terus mengadakan kegiatan seminar, pengajian, pengkaderan, pelatihan, seperti yang telah dilaksanakan yakni Pendidikan Kader Penggerak Nahdlatul Ulama (PKPNU), Pelatihan Kader Dakwah dan untuk Muhammadiyah hendaknya terus mengadakan kajian rutin, berdakwah sosial, karena itu semua sangat berguna bagi jama'ah, masyarakat dan para pelajar untuk menambah pengetahuan dan juga sebagai bentuk upaya untuk menangkal radikalisme.

\section{DAFTAR PUSTAKA}

Al-Qur"an Terjemahan. Departemen Agama RI. Ed, Bandung: CV Darus Sunnah, 2015 Anwar Arifin,2011, Dakwah Kontemporer: Sebuah Studi Komunikasi, Yogyakarta: Graha Ilmu Asfar, Muhmmad, 2003, ed, Islam Lunak Islam Radikal Pesantren, Terorisme Dan Bom Bali, Surabaya: Jp Pres.

Asror Ahidul, 2018, Paradigma Dakwa Konsepsi dan Dasar Pengembangan Ilmu, Yogjakarta,LkiS.

Aziz, A.M,2009 Ilmu Dakwah, Jakarta: Prenada Media

Aziz,Ali, M, 2004, Ilmu Dakwah, Jakarta:Kencana.

Christina Parolin, Radikal Spaces: Venues of Popular in London, 1790-c.1845 (Australia: ANU E Press, 2010), Cet. Ke-1, 
Edy Sumtaki, 2003, et al. Syari'at Urgensi dan Konsekuensinya Islam: Sebuah Bunga Rampai, Jakarta: Komunitas NISITA

Hasse J.M,R, Radikalisme Agama Legitimasi Tafsir Kekerasan di Ruang Publik, Jurnal Al-Ulum. Volume 16. Number 2. Desember 2016

Ninin Prima Damayanti, dkk,,"Radikalisme Agama Sebagai Salah Satu Bentuk Perilaku Menyimpang: Studi Kasus Front Pembela Islam”, Depok: Universitas Indonesia, Jurnal Kriminologi Indonesia Vol. 3 No. I Juni 2003

Sanusi, 1985, Pengantar Studi Ilmu Dakwah, Semarang: Fakultas Dakwah IAIN Walisongo.

Siddhiq Ahamad, 2005, Khittah Nahdliyyah, Khalista, Surabaya

Soleh, Muhammad Khomsun, 2019, Menangkal Masuknya Paham Radikalisme Pada Masyarakat Desa,Temanggung, Jawa Tengah

Sugiono,2011, Metode Peneitian Kuantitatif Kualitatif R\& D, Bnadung: Alfabeta.

Suhandang Kustadi, 2009, Retorika: Strategi, Teknik dan Taktik Berpidato, Bandung: Penerbit Nuansa

Sutarto, Ayu, 2008, Menjadi NU Menjadi Indonesia, Pemikiran KH Abdul Muchith Muzadi, Surabaya :Kompyawisda jatim dan Khalista

Sutinah, Bagong Suyanto, 2013, Metode Penelitian Sosial, Jakarta: Prenadamedia Group.

Syukir,Asmuni,1983, Dasar Dasar Startegi Dakwah Isalam,Surabaya: Al-Ikhlas.

Uchjana Effendy Onong,2007, Ilmu Komunikasi: Teori dan Praktek, Bandung: PT Remaja Rosdakarya

Weinata, Sairin Weinata,1995, Gerakan Pembaharuan Muhammadiyah, Jakarta: Pustaka, Sinar Harapan

Yaqin Ainul, 2005, Pendidikan Multikultural Cross-cultural Understanding untuk Demokrasi dan Keadilan, Pilar Media, Yogyakarta.

\section{Sumber Internet :}

http://rri.co.id/madiun/post/berita/240536/daerah/isis_pengaruhi_siswa_sd_di_b ondowoso.html

http://www.muhammadiyah.or.id/id/content-51-det-anggaran-dasar.html.

https://id.wikipedia.org/wiki/Bom_Bali_2002.

https://id.wikipedia.org/wiki/Bom_Bali_2005. 
https://id.wikipedia.org/wiki/Pengeboman_Hotel_Marriott_2003.

https://id.wikipedia.org/wiki/Pengeboman_Jakarta_2009.

https://nasional.kompas.com/read/2016/01/17/05300041/Ini.Kronologi.Teror.B om.Jakarta.dari.Detik.ke.Detik.

https://rumaysho.com/10708-islam-benci-radikalisme.html

https://www.bangsaonline.com/berita/21300/provokatif-34-pengasuh-pesantrenminta-aparat-batalkan-acara-syiah-di-bondowoso

https://www.cnnindonesia.com/nasional/20190604110800-20-400871/rentetanbom-dan-aksi-terorisme-selama-ramadan-di-indonesia.

https://www.eramuslim.com/berita/nasional/update-inilah-kronologipembakaran-masjid-di-wamena-oleh-teroris-kristentolikara.htm\#.XaxMnn8xXMx.

http://jurnalptiq.com/index.php/andragogi/article/view/47

http://hizbuttahrirhti.blogspot.com/2014/02/lds-hti-jember-berikanpenyuluhan.html? $\mathrm{m}=1$

http://ditjenpp.kemenkumham.go.id/arsip/ln/2018/uu5-2018bt.pdf 

Muhammadiyah dalam Menangkal Radikalisme di Kabupaten Bondowoso 